\title{
Talent Management an Emerging Trend for Employee Effectiveness in Corporate Hospitals
}

\author{
S. Malathi, M. Ayisha Millath
}

\begin{abstract}
Talent management is considered an important factor for attaining competitive advantage and development of the firm in the current era. It deals with filling a vacant position with a talented workforce than a skilled workforce for the long-run objective of the firm. The present study was carried with an objective to identify the effectiveness of talent management practices and strategies in corporate hospitals. The study was conducted with 290 respondents in corporate hospitals in the Madurai district using a structured questionnaire. The result indicates the intention of talent management practices and strategies was; to build a deeper reservoir of successors at every level, creating a culture that makes employees stay with the firm and to identify gaps in the current workforce and their competency level. But, the talent management practices and strategies are effective in; Aligning workforce with the mission and vision of the organization, creating suitable policies that encourage individual career growth and development opportunities and Identifying and locating the qualified professionals needed.
\end{abstract}

Keywords: Talent management; intension of talent management; impact of talent management.

\section{INTRODUCTION}

Talent Management is a systematic and strategic process of identifying vacant positions in an organization and filling it with the right employee or employer having sufficient knowledge, skill and expertise to achieve long term objectives of the firm. The growth of talent management was sensed only during the past decade when the companies looked for retaining more skillful and expertise individuals to attain competitive advantage and the strategic vision, mission, and objectives of the company. Management was the key concern were individuals with different skill set are integrated to work for the Earlier to talent management,human resource development of the organization, while before Human resource management it was personnelmanagement i.e. the employees are trained to perform routine and specific job in manufacturing sector wherein the management decision are taken only by the business owners (business Jargons, 2019).

Considering the modern society and changes undergone in culture, many hospitals are facing numerous challenges such as the aging population, increasing competition, government restriction, lack of technology and lack of skillset to provide treatment to certain diseases(Hendriks, Ligthart, \& Schouteten, 2016).

Revised Manuscript Received on December 05, 2019.

S.Malathi, Research Scholar, Alagappa Institute of Management Alagappa University, Karaikudi.

Email :malathi86yahoo.co.in

Dr. M.Ayisha Millath, Assistant Professor, Alagappa Institute of Management, Alagappa University, Karaikudi.

Email:ayishamillath05@gmail.com
Effective integrationof departmentsand talents of individuals may able to impart successful business practices through effective management decisions. Further talent management practices provides constant updates to every stakeholder working within the hospital; Physicians are updated with new medical procedure to treat a particular disease, Management is provided with updated information to make effective decision in relation to infrastructure, technology, customer inconvenience, service quality, competitor strategy and so on to strive competitive advantage in the industry.

The length and depth of the hospital industry are growing due to increasing patient with a new disease, a complication in insurance, quality treatment provided at the hospital and government policies(Sch€afer, 2010). Talent Management plays are a prime role in making a benchmark in a current era yet it is not detected to be a significant criterionin many hospitals. Hereby the current study focuses on measuring the intention and impact of talent management practices in corporate hospitals situated inthe Madurai region.

\section{REVIEW OF LITERATURE}

Healthcare sector is considered to be one among the gigantic industry augmenting at a remarkable phase in many directions such as telemedicine, electronic appointment, healthcare information system, computerized health record, $\mathrm{m}$-health, and digital health knowledge resource and so on (Groves, Kayyali, Knott, \&Kuiken, 2016). This phenomenal change in the healthcare sector had imparted a change in consumer perception, awareness and completely modified the treatment-seeking behavior of an individual (Goh \& Marimuthu, 2016). The phenomenal change had imparted a sharp increase in demand as well as intensified the competition within the industry (Fadhil, Jusop, \& Abdullah, 2012).

To overcome the competition and to attain a competitive advantage especially in the service sector such as healthcare, talent management had become a top priority worldwide (Chuai, Preece, \& Iles, 2008). It was discussed by various reviews that change in the demographic labor market, shortage of skills and ever ending consumer demand had imposed 'wat for talent' (Tansley, Harris, Stewart, Turner, \& Williams, 2006). Furthermore, every organization is seeking to improve its policies, practices and strategies to recruit, develop and retain talent successfully within their organization (Tarique \& Schuler, 2010). Hereby the current study focuses on gap existing between talent management practices and strategies intention and impact. 


\section{OBJECTIVES}

- To understand the concept of talent management fromthe perspective of corporate hospitals.

- To measure the priority given to talent management in Small, Medium and Large size corporate hospitals.

- To identify the intension of talent management practices and strategies in corporate hospitals.

- To ascertain the impact of talent management practices and strategies in corporate hospitals

\section{METHODS}

The study adopted a descriptive research design. The data was collected from 290 human resource managers and supervisors belonging to corporate hospitals. The data were collected using a structured questionnaire. The study area was confined to the Madurai district situated at Tamil Nadu, India. The data was collected during the year 2018-19.

\section{ANALYSIS AND INTERPRETATION}

Table - I: Talent Management initiatives as a top priority

\begin{tabular}{|c|c|c|c|}
\hline \multicolumn{4}{|c|}{ Talent Management initiatives as a top priority } \\
\hline $\begin{array}{c}\text { Average } \\
{[\mathbf{n}=\mathbf{2 9 0}]}\end{array}$ & $\begin{array}{c}\text { Small } \\
{[1-99} \\
\text { Employees] } \\
{[\boldsymbol{n}=\mathbf{9 4}]}\end{array}$ & $\begin{array}{c}\text { Medium } \\
{[100-499} \\
\text { Employees] } \\
{[\mathbf{n = 1 0 4 ]}}\end{array}$ & $\begin{array}{c}\text { Large } \\
{[\text { Above }} \\
\mathbf{5 0 0 ]} \\
{[\mathbf{n}=\mathbf{9 2}]}\end{array}$ \\
\hline $78 \%$ & $75 \%$ & $69 \%$ & $90 \%$ \\
\hline
\end{tabular}

Source: (Primary Data)

From the study conducted, it can be interpreted that $90 \%$ of the large scale companies, $69 \%$ of the medium-scale companies and $75 \%$ of the small scale companies consider talent management initiative as a top priority.

Figure - 1: Managers working directly with employees in Talent Management initiatives

\section{Talent Management Initiatives}

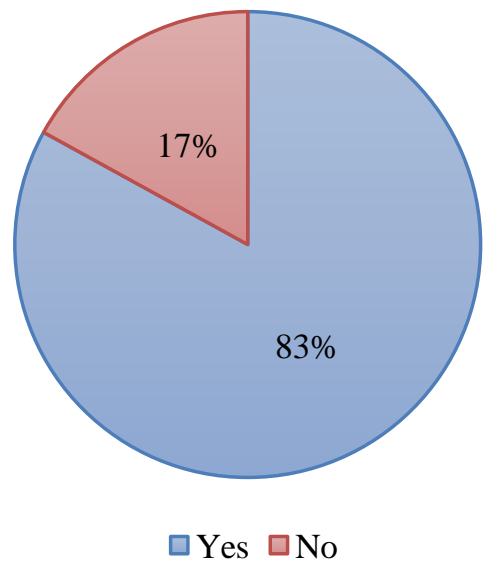

\section{Source: (Primary Data)}

It is understood from the study that $83 \%$ of the respondents have made talent management initiatives in their company's.

Table - II: Intension of Talent Management Practices and Strategies

\begin{tabular}{|l|l|l|l|l|l|l|l|l|}
\hline Item & Talent Management Practices and Strategies & $\begin{array}{l}\text { SD } \\
{[\mathbf{1}]}\end{array}$ & $\begin{array}{l}\mathbf{D} \\
{[\mathbf{2}]}\end{array}$ & $\begin{array}{l}\text { NDNA } \\
{[\mathbf{3}]}\end{array}$ & $\begin{array}{l}\mathbf{A} \\
{[\mathbf{4}]}\end{array}$ & $\begin{array}{l}\text { SA } \\
{[\mathbf{5}]}\end{array}$ & $\begin{array}{l}\text { Total } \\
\text { Score }\end{array}$ & $\begin{array}{l}\text { Ran } \\
\mathbf{k}\end{array}$ \\
\hline 1 & Building a deeper reservoir of successors at every level & 2 & 10 & 3 & 22 & 63 & 434 & 1 \\
\hline 2 & Creating a culture that makes employees to stay with the firm & 2 & 7 & 14 & 18 & 59 & 425 & 2 \\
\hline 3 & Identifying gaps in current workforce and their competency level & 6 & 4 & 11 & 21 & 58 & 421 & 3 \\
\hline 4 & $\begin{array}{l}\text { Creating suitable policies that encourage individual career } \\
\text { growth and development opportunities }\end{array}$ & 10 & 1 & 18 & 14 & 57 & 407 & 5 \\
\hline 5 & $\begin{array}{l}\text { Identifying vacancies that will be created as the organization } \\
\text { expands }\end{array}$ & 3 & 8 & 11 & 35 & 43 & 407 & 5 \\
\hline 6 & Identifying and locating the qualified professionals needed & 2 & 11 & 14 & 22 & 51 & 409 & 4 \\
\hline 7 & Rewarding top-performers & 8 & 8 & 22 & 21 & 41 & 379 & 10 \\
\hline 8 & Creating an environment that excites employees to come to work. & 4 & 12 & 18 & 28 & 38 & 384 & 8 \\
\hline 9 & $\begin{array}{l}\text { Aligning workforce with the mission and vision of the } \\
\text { organization }\end{array}$ & 2 & 7 & 17 & 38 & 36 & 399 & 7 \\
\hline 10 & Assessing candidates' skillset during the hiring process & 11 & 7 & 15 & 34 & 33 & 371 & 11 \\
\hline 11 & Creating a culture that values employees' work & 5 & 19 & 22 & 26 & 28 & 353 & 13 \\
\hline 12 & $\begin{array}{l}\text { Creating a culture that makes individuals want to join the } \\
\text { organization }\end{array}$ & 7 & 4 & 28 & 22 & 39 & 382 & 9 \\
\hline 13 & $\begin{array}{l}\text { Creating an environment where employees' ideas are listened as } \\
\text { well as valued }\end{array}$ & 10 & 16 & 19 & 18 & 37 & 356 & 12 \\
\hline
\end{tabular}

Source: (Primary Data)

Through the study it was understood that the intention of the talent management practice was; to build a deeper reservoir of successors at every level, creating a culture that makes employees to stay with the firm and to identify gaps in current workforce and their competency level. 
Table - III: Impact of Talent Management Practices and Strategies

\begin{tabular}{|c|c|c|c|c|}
\hline Item & Impact of Talent Management Practices and Strategies & Agree & Disagree & $\begin{array}{c}\text { Rank based } \\
\text { on Agree }\end{array}$ \\
\hline 1 & Building a deeper reservoir of successors at every level & 58 & 42 & 5 \\
\hline 2 & Creating a culture that makes employees to stay with the firm & 47 & 53 & 13 \\
\hline 3 & Identifying gaps in current workforce and their competency level & 56 & 44 & 7 \\
\hline 4 & Creating suitable policies that encourage individual career growth and \\
development opportunities & 62 & 38 & 2 \\
\hline 5 & Identifying vacancies that will be created as the organization expands & 54 & 46 & 8 \\
\hline 6 & Identifying and locating the qualified professionals needed & 61 & 39 & 3 \\
\hline 7 & Rewarding top-performers & 53 & 47 & 9 \\
\hline 8 & Creating an environment that excites employees to come to work. & 51 & 49 & 10 \\
\hline 9 & Aligning workforce with the mission and vision of the organization & 63 & 37 & 1 \\
\hline 10 & Assessing candidates' skillset during the hiring process & 60 & 40 & 4 \\
\hline 11 & Creating a culture that values employees' work & 57 & 43 & 6 \\
\hline 12 & Creating a culture that makes individuals want to join the organization & 48 & 52 & 12 \\
\hline 13 & Creating an environment where employees' ideas are listened as well as & 51 & 49 & 10 \\
\hline
\end{tabular}

\section{Source: (Primary Data)}

Despite the intention of the talent management practices and strategies, they produce a significant impact in; Aligning workforce with the mission and vision of the organization, Creating suitable policies that encourage individual career growth and development opportunities and Identifying and locating qualified professionals needed.

Table - IV: Intension \& Impact of talent management practices and strategies

\begin{tabular}{|l|ll|l|l|}
\hline $\begin{array}{l}\text { Pearson } \\
\text { Correlation }\end{array}$ & $\begin{array}{l}\text { Intention } \\
\text { Impact }\end{array}$ & $\boldsymbol{V}$ & $\boldsymbol{R}$ & Sig. \\
\cline { 3 - 4 } & & 0.26 & 0.468 \\
\hline
\end{tabular}

\section{Source: (Primary Data)}

From the significance value estimated it can be interpreted there is no significant relationship between the intentions and impact of talent management practices and strategies

\section{CONCLUSION}

The analysis made using 290 respondents from corporate hospital illustrates that talent management is considered as the top priority irrespective of corporate hospital size. Further, the result indicated that $83 \%$ of the firms had taken initiatives regarding talent management. It is to be noted that, there is no significant relationship between the intention and impact of talent management practices and strategies. It was found that, the intention of talent management practices and strategies was; to build a deeper reservoir of successors at every level, creating a culture that makes employees stay with the firm and to identify gaps in the current workforce and their competency level. But, the talent management practices and strategies are effective in; Aligning workforce with the mission and vision of the organization, creating suitable policies that encourage individual career growth and development opportunities and Identifying and locating the qualified professionals needed. Though the intention and impact of talent management are different yet, they help in progressing the firm through a talented workforce.

\section{REFERENCES}

1. Business Jargons. (2019). Retrieved from businessjargons.com: https://businessjargons.com/talent-management.html
2. Chuai, X., Preece, D., \& Iles, P. (2008). Is talent management just "old wine in new bottles"? The case of multinational companies in Beijing. Management Research News, 31(12), 901-911.

3. Fadhil, ., Jusop, ., \& Abdullah, . (2012). Hospital Information System(His) Implementation In A Public Hospital:A Case Study From Malaysia. Far East journal of psychology and business, 8(1), 111.

4. Goh, ., \& Marimuthu, . (2016). The Path towards Healthcare Sustainability:The Role of Organisational Commitment. . Procedia: Social and Behavioral Sciences, 224, 587-592; doi:10.1016/j sbspro.2016.05.445.

5. Groves, ., Kayyali, ., Knott, ., \&Kuiken, . (2016). The'bigdata' revolution in healthcare: Accelerating value and innovation.

6. Hendriks, P. H., Ligthart, P. E., \& Schouteten, R. L. (2016) Knowledge management, health information technology and nurses work engagement. Health Care Management Review, 41, 256-266.

7. Sch€afer, W. (2010). The Netherlands- Health system review. Health Systems in Transition, 21(1), 1-229.

8. Tansley, C., Harris, L., Stewart, K., Turner, P. F., \& Williams, H. (2006). Talent management: Understanding the dimensions change agenda . London, England: CIPD.

9. Tarique, I., \& Schuler, R. S. (2010). Global talent management: Literature review, integrative framework, and suggestions for further research. Journal of world business, 45(2), 122-133. 